Delnoij, D., Brenner, G.

Importing budget systems from other countries: what can we learn from the

German drug budget and the British GP fundholding?

Health Policy: 52, 2000, nr. 3, p. p. 157-169

\begin{tabular}{|l|l|}
\hline Postprint Version & 1.0 \\
\hline Journal website & $\underline{\text { http://dx.doi.org }}$ \\
\hline Pubmed link & $\begin{array}{l}\text { http://www.ncbi.nlm.nih.gov/entrez/query.fcgi?cmd=Retrieve\&db=pubmed\&dop } \\
\text { t=Abstract\&list_uids=10862991\&query_hl=49\&itool=pubmed_docsum }\end{array}$ \\
\hline DOI & $\underline{10.1016 / S 0168-8510(00) 00074-9}$
\end{tabular}

* Corresponding author. Tel.: +31-30-2729700; fax: +31-30-27292729.

E-mail address: d.delnoij@nivel.nl (D. Delnoij)

\title{
Importing budget systems from other countries: what can we learn from the German drug budget and the British GP fundholding?
}

DiAnA DELNOIJ ${ }^{\mathrm{A},}$, GERHARD BRENNER ${ }^{\mathrm{B}}$

a NIVEL, PO Box 1568, 3500 BN Utrecht, The Netherlands

b Zentralinstitut für die Kassenärztliche Versorgung in der Bundesrepublik Deutschland, Hoeninger

Weg 115, 50969 Cologne, Germany

\begin{abstract}
The rising costs of pharmaceutical expenditures are a common problem for policy makers in most European countries. In two countries, budget systems for pharmaceutical spending exist(ed). In Great Britain, between 1991 and 1999 GP fundholders were responsible for prescribing costs, and in Germany an overall expenditure cap for pharmaceutical prescribing has been used since 1993. These two examples are analysed in order to identify the conditions that are needed for successfully implementing budget systems for prescribing costs in other countries. It is argued, that a good budget system balances the provision of enough information for budget holders to monitor their expenditures on the one hand, against an explosive increase of transaction costs on the other hand. Apart from that, it makes doctors responsible only for expenditures that they themselves can actually control, and does not provide them with an incentive to use that discretionary power by shifting expenditures to other health care sectors. A good information infrastructure is needed for the implementation of budget systems in general. For the introduction of fundholding, a number of additional criteria need to be met, such as having gate-keeping GPs with personal lists and having a single-payer system.
\end{abstract}

\section{INTRODUCTION}

In general, all modern health care systems face the same type of problems, that can be summarised as ensuring quality of care and equity, macro-economic cost control and micro-economic efficiency [1]. An area of concern for policy makers in most European countries are the ever-rising expenditures on pharmaceuticals. Fig. 1 shows the average increase since 1980 of pharmaceutical expenditures as a percentage of gross domestic product (GDP) in the 15 countries of the European Union. The boxes represent the range within which the spending on pharmaceuticals in the 15 Member States fall. The minimum percentage of GDP (the 'bottom' of the box) was spent throughout the period 1980-1995 in Denmark, the maximum percentage (the 'top' of the box) was spent in Portugal. The mean percentage for the EU has risen from about 0.9 to $1.2 \%$ of GDP. The increasing size of the boxes indicates that the variation in spending between EU Member States has increased over the years. 
Delnoij, D., Brenner, G.

Importing budget systems from other countries: what can we learn from the

German drug budget and the British GP fundholding?

Health Policy: 52, 2000, nr. 3, p. p. 157-169

\section{[ FIGURE 1 ]}

In order to control the expenditures on pharmaceutical care, most European countries have introduced price controls and cost sharing [2]. Judging from Fig. 1, this has not had the desired effect.

The problem with price controls is that expenditures can still rise due to increases in the volume of drugs. This problem does not occur when pharmaceutical expenditures are budgeted. Budget systems for pharmaceutical expenditures have been used in only two countries. Between 1991 and 1999 in Great Britain, GP fundholders were responsible for prescribing costs, along with a number of other services, and in Germany an overall expenditure cap for pharmaceutical prescribing has been used since 1993 in addition to already existing budgets for physicians' services and hospital care.

Using the British GP fundholding system and the German ambulatory drug budget as examples, we shall describe the effects of budget systems in controlling pharmaceutical spending and the problems that are associated with applying budget systems. In doing so, we aim to identify the conditions that are needed for successfully implementing budget systems for prescribing costs in other countries.

\section{GP FUNDHOLDING}

\subsection{The system}

In the UK, practices with more than 5000 patients could voluntarily hold the budget for elective surgery, for outpatient care, diagnostic testing, community nursing, and for prescribing costs. This budget was generally based on historical costs (the spending in the preceding year), though the budgets could also be adjusted based on health authorities' perceptions of the needs of a practice population. Fundholders could negotiate with the health authority in order to secure a higher budget [3]. Apart from the 'traditional' fundholding, there were two other schemes: community fundholding, in which the budget did not contain costs of outpatient hospital care, and total purchasing, giving GPs the authority to purchase all services provided by the NHS, including inpatient care. Community fundholding was open to all practices with a minimum of 3000 patients. The minimum number required for 'traditional' fundholding had gradually been reduced. At the outset of the system (1991), a minimum of 11000 was required [4]. Fundholding practices needed to have a relatively large number of patients in order to minimise financial risk due to random fluctuation in morbidity [5]. Under fundholding, there were 'stop-loss' arrangements for patients costing more than $£ 6000$ a year. A possible surplus on the budget could be used to improve patient care. It could not be used as extra income.

General practitioners could participate in the GP fundholding scheme on a voluntary basis. Each year in April, another so-called wave of GPs entered the system. The first wave of fundholders entered the scheme in April 1991. By 1996, already half of the English population was served by a fundholding practice [4]. The idea of fundholding was based on 'Working for Patients'; a white paper published by the British government in 1989. 'Working for Patients' contained an outline of the purchaser-provider split that has been implemented in the NHS. 'Working for Patients' was conceived under the conservative government. However, in 1997 the Labour Party announced the abolishment GP fundholding from April 1999 in the white paper 'The New NHS' [6]. Although GP fundholding has now been abolished, groups of GP practices (primary care groups) covering geographical communities of up to a population of 100000 will be responsible for purchasing hospital, community and primary care for their populations [7].

\subsection{Effects}

The effects of fundholding have been reviewed by Coulter [8], Gosden and Torgerson [9], and most extensively by Le Grand et al. [7]. Coulter concluded that fundholding had not affected GPs' referral rates to specialists and hospital (though GPs did purchase outpatient care and elective surgery, and thus had an interest in low referral rates). However, some effect of fundholding could be demonstrated on prescription costs. Gosden and Torgerson regard the evidence on referral rates complex to interpret. According to Gosden and Torgerson [9] too, prescribing costs of fundholding practices increased at a lower rate compared with non-fundholders.

Several studies [3,4,7,9-13] have demonstrated this effect. In general, fundholders' prescribing costs grew at a lower rate than costs of non-fundholders, not because they prescribed fewer drugs, but 
Delnoij, D., Brenner, G.

Importing budget systems from other countries: what can we learn from the

German drug budget and the British GP fundholding?

Health Policy: 52, 2000, nr. 3, p. p. 157-169

because they switched to cheaper (generic) drugs. This was observed especially in the first waves of fundholders. The differences were much smaller when comparing later waves of fundholders and nonfundholders [3,4,7,13]. Apart from that, Stewart-Brown et al. [14] found, in a follow-up of Bradlow and Coulter's study [10], that the lower costs per prescription of fundholding practices in the first year of fundholding had changed into significantly higher costs than those of non-fundholding practices after 3 years of participating in the scheme.

\subsection{Problems}

Problems associated with fundholding can be grouped under the following three headings: the budget formula; administrative costs; and selection.

\subsubsection{The budget formula}

Since the budget was based on historical costs rather than on the needs of the population, past inefficiencies were rewarded, whereas efficient behaviour in the year preceding fundholding is punished. The budget formula also provided doctors with an incentive to 'artificially' increase the costs of care in the year before entering the scheme. There was no evidence that such an adverse effect had indeed occurred [3], though some authors offer it as a possible explanation for the fact that after 3 years of fundholding beneficial effects on prescription costs have faded away [7,14]. However, Le Grand et al. [7] also report on evidence that some GPs - e.g. in Northern Ireland, where prescribing budgets are set explicitly on the previous year's actual expenditure - with 2 years of savings had had their drug budgets subsequently reduced by Family Health Service Authority. This left them with little incentives to continue with rational prescribing.

\subsubsection{Administrative costs}

The Audit Commission has conducted a study into the costs and benefits of fundholding. They conclude that the costs associated with fundholding did not outweigh the savings of the system. Compared to running an 'ordinary' general practice, fundholding calls for a number of extra administrative tasks (such as monitoring referrals, updating patient records, checking and processing claims, etc.) that either have to be conducted in the general practice itself by a practice - or fundmanager, or that are delegated to a so-called multifund in which a number of fundholders cooperate with regard to purchasing and administration. Early 1995, the management — and transaction costs of fundholding had added to $£ 232$ million, whereas the savings that were realised by fundholders were estimated to be about $£ 206$ million [4].

\subsubsection{Selection}

Finally, because of the voluntary nature of the fundholding scheme, fundholders were a selective group of GPs. Fundholding practices were larger, better equipped and generally located in more affluent regions than non-fundholding practices [8]. Apart from that, the volunteers received considerable investment to support the new responsibilities which accompanied fundholding or trust status. This included financial investment through computer and management allowances, and investment of the time and energy of managers from the local and regional health authority and local trusts [7].

This implies that the effect of fundholding for instance on prescribing costs may have been typical for this selection of GPs. Maybe less well organised practices would not have been able to accomplish the same. It also implies that any positive effects that fundholding has had on the provision of care (e.g. through re-investment of savings) were reserved for the richer part of the population. In other words, fundholding may have led to a two-tier system [8], which is one of the reasons for the abolishment of the scheme by the Labour government [6]. Abolishment of the system was also claimed to lead to a reduction of management and administrative costs [7]. 
Delnoij, D., Brenner, G.

Importing budget systems from other countries: what can we learn from the

German drug budget and the British GP fundholding?

Health Policy: 52, 2000, nr. 3, p. p. 157-169

\section{THE GERMAN DRUG BUDGET}

\subsection{The system}

In Germany, an overall expenditure cap on (pharmacy-only) prescribing costs generated by ambulatory physicians, has been imposed by law in 1993 as part of the comprehensive Health Care Reform Act $[15,16]$. Overall expenditure caps already existed for physician services, hospital care, and auxiliary services. Unlike the GP fundholding budgets, the German caps are sectional budgets: a surplus in one area cannot be invested in another sector. Between 1993 and 1995 the level of pharmaceutical spending was prescribed by law. Since 1995 this level has been subject to regional negotiations between sickness funds and physician associations. The initial expenditure cap for 1993 was determined on the basis of the expenditures in 1991, but it had been corrected for factors such as population growth and inflation.

The nation-wide drug budget is distributed over 23 regions, and a surplus in one region cannot compensate for a deficit in another region. In case a regional budget is exceeded, according to the law (Social Security Code, 5th Book), the regional physician associations pay the deficit. In negotiations, sickness funds and physician associations later agreed that doctors would first have the opportunity to compensate for a deficit by lower expenditures in the next year.

In 1993 only, doctors' liability was limited to 1\% of their total fees, or 280 million DM [16]. After this first year, ambulatory physicians would be held fully responsible for any excess spending. There are no positive incentives in the German system: doctors are not allowed to keep the difference in case they spend less than the given budget, though at the moment experiments are taking place with positive incentives.

\subsection{Effects}

In Fig. 2, prescriptions and sales of drugs of ambulatory care physicians between 1981 and 1996 in Germany is presented.

\section{[ FIGURE 2 ]}

After the introduction of the budget, the number of prescriptions dropped to a level that was lower than that of 1991, on which the budget was based. This profound decrease is largely due to the initial shock that the threat of the compensation posed to physicians. Apparently, the 'good' result for 1993 softened the first shock, because after 1994 the number of prescriptions started to rise again, and in 1995 for the first time, the costs exceeded the budget in 9 out of 23 regions.

\subsection{Problems}

The exceeding of the budget in nine regions brought out the flaws in the German budget system. It has two major problems, concerning the justice of the system, and concerning unintended effects.

\subsubsection{Justice}

When the budget was exceeded in the nine regions, the sickness funds held doctors financially responsible for this deficit. The doctors, in turn, challenged the legal status of these demands. They claimed the system was unfair because:

- Firstly, there was no related individual drug budget per physician. Therefore, it had never been clear how the fines would be distributed. Von der Schulenburg [17] compares the budgeting for outpatient drugs to: '.. driving on a highway, knowing that there is a speed limit, but not knowing how high it is or how the total fines will be distributed among the drivers'. Distributing the deficit evenly over all doctors would be unfair towards doctors that hardly prescribe any medication (for example radiologists). It would also be unfair towards doctors that have tried to prescribe rationally. On the other hand, laying the burden on those who prescribe the most (GPs and specialists in internal medicine) threatened to bring practices on the verge of bankruptcy.

- Secondly, it was not until August 1996 that it became clear the budget for 1995 had been exceeded. This left the ambulatory physicians with very little time to compensate for the deficit in the year after, as they were allowed to do as a result of negotiations with the sickness funds. For this reason, the physician associations threatened to take their case to court if they would indeed be made liable. This has resulted in a stalemate, which is as yet unresolved. It was intended to 
Delnoij, D., Brenner, G.

Importing budget systems from other countries: what can we learn from the

German drug budget and the British GP fundholding?

Health Policy: 52, 2000, nr. 3, p. p. 157-169

replace the global expenditure cap by individual budgets from 1996 onwards. These microbudgets would take the form of speciality-related prescription limits. But the physicians' associations have not yet accepted this solution, because they cannot monitor the prescription limits, due to the lack of physician-related data $[16,18]$.

\subsubsection{Unintended effects}

Apart from that, the German system has had unintended effects. In anticipation of the drug budget, the cost and volume of prescriptions showed a significant increase in the final quarter of 1992: the year before the budget came into effect [19]. More importantly: two studies have provided evidence for a simultaneous increase in referral rates and hospital admissions [19,20]. The number of referrals and hospital admissions showed a statistically significant increase after the introduction of the drug budget, which applies only to prescriptions in ambulatory care. However, the causal relation between this phenomenon and the introduction of the drug budget is in dispute, because together with the drug budgets other important changes took place in the health care system (e.g. a new planning system, and the introduction of the chip card).

\section{WHAT CAN WE LEARN FROM THE GERMAN AND BRITISH EXAMPLE?}

From the British and German example, there are several conclusions that can be drawn with regard to the effectiveness of budget systems and the conditions under which they function.

First of all, it is evident that the level at which the budget is implemented is an important factor. The German example shows that under an overall expenditure cap, monitored at the level of a whole country or a large region, doctors have to bear the consequences of the behaviour of others, whom they do not know and on whose behaviour they have no influence at all. This is caused by a conflict between the individual and the collective interest [21]. This conflict can be bridged by making providers responsible for micro-budgets, e.g. on the level of group practices, as was the case in the British GP fundholding system. From doctors' point of view therefore, the level of group practices which was used in the British fundholding system, is to prefer over the German level of regions.

Secondly, it must be possible to provide doctors with frequent feedback on their behaviour. Because there was no individual budget, in Germany this proved to be one of the bottlenecks of the system. Doctors need to know how much of the budget they have already spent, and on which services. Without such information, doctors cannot rationally monitor their own behaviour in order to stay within the budgetary limits.

Thirdly, from the fundholding example we learn that, preferably a budget system is administratively simple so as to contain overhead costs. Partly of course, fundholding had high transaction costs because the purchasing activities of GPs required a management and information system that had the capacity to process bills. The German budget system, which is in fact an expenditure cap that takes effect only if expenditures exceed the limit defined ex ante, does not require the processing of bills by doctors or their practice managers. German doctors do not actually get an amount of money from which they can purchase pharmaceuticals for their patients. This implies that claims are processed as usual, namely by the sickness funds.

Finally, the German debate on the increased hospital costs after introducing the drug budget, shows that one should monitor unintended effects when dealing with the well-known health care balloon. Squeezing the prescribing costs could result in higher expenditures for specialist or hospital care.

So all in all, from the German and British example one can learn, that in designing a budget system policy makers must balance between (1) the provision of enough information for budget-holders to monitor their expenditures on the one hand, and (2) an explosive increase of transaction costs on the other hand; and between (3) making doctors responsible only for expenditures that they themselves can actually control on the one hand, and (4) not providing them with an incentive to use that discretionary power by shifting expenditures to sectors for which they are not liable on the other hand. To some extent, however, these four conditions are contradictory. For example, Condition 4 is best met by introducing total purchasing, because it is no use to shift expenditures to another health care sector if all health care expenditures fall under the same budget. At the same time, this violates Condition 3: total purchasing implies that GPs are responsible for e.g. inpatient hospital care. Now, GPs do take the decision to refer a patient, so they can be held partly responsible for outpatient 
Delnoij, D., Brenner, G.

Importing budget systems from other countries: what can we learn from the

German drug budget and the British GP fundholding?

Health Policy: 52, 2000, nr. 3, p. p. 157-169

hospital costs. But, once a patient has been referred, the decision to admit him or her to the hospital is taken by a hospital physician.

Similarly, it can be argued that doctors have more control over expenditures if they are true fundholders, that is if they actually get the money from which to purchase care for their patients instead of some fictional budget that only becomes real to them once it is exceeded. At the same time though, fundholding might generate higher transaction costs (Condition 2) than monitoring an expenditure cap. The choice for a specific design depends on (political) characteristics of the health care system and the technical context (e.g. the information infrastructure) in which a budget system must be implemented [22,23].

\section{CAN OTHER COUNTRIES IMPORT THE BRITISH OR GERMAN BUDGET SYSTEM?}

Our primary aim in describing the German and British budget systems for pharmaceutical spending, was to identify the conditions that need to be met for a successful implementation of pharmaceutical budgets in other countries. Policy makers tend to look across the borders of their national health systems for (supposedly) effective solutions to the shared problems of micro- and macroeconomic efficiency. There are several examples of countries that have 'imported' specific features from foreign health care systems. In Norway and Finland, for example, personal lists for GPs (common in the UK, Denmark, the Netherlands and other countries with a strong primary care system) have been introduced in the last decade [24,25]. Another example is the introduction of Diagnosis Related Groups (originally stemming from the US) in hospital payment in Hungary [26] and lump-sums for defined surgical procedures in German hospitals. And the British GP fundholding, for instance, was inspired by American Health Maintenance Organizations [27]. GP fundholding, in turn, appeals to policy makers and GPs abroad [2]. In the Netherlands, for instance, where the role and position of GPs is similar to that of British GPs, the introduction of fundholding in general practice has been advocated several times $[28,29]$.

Although it is quite understandable and also efficient if policy makers do not re-invent the wheel, policy instruments that are effective in one country need not always be successful in other countries. As Saltman [22] puts it: '... health systems are deeply embedded within the social and cultural fabric of each society'. Health systems are historically determined constellations of characteristics and, possibly, the effectiveness of policy instruments such as budgets for pharmaceutical prescribing is dependent on specific combinations of characteristics.

Fundholding, for instance, is only possible in countries where GPs have fixed patient lists and where GPs serve as gatekeepers to specialist care. Otherwise, whose funds would GPs hold and how would they be able to monitor the budget, if patients can see other doctors without the GP knowing? This implies that GP fundholding - the way it is implemented in the UK - is no option in the current health care systems of, e.g. Germany, Austria, France or Belgium. It could theoretically be introduced in other gatekeeper countries, such as Spain, Portugal, Ireland, Denmark and the Netherlands.

The difficulty in the Netherlands and to some extent also in Ireland, however, is that in those countries there is no single-payer in health care. In the Netherlands, for instance, health insurance is operated through more than 20 public sickness funds and a number of private health insurance companies. The sickness funds used to have regional monopolies, but since 1991 they are allowed to offer public insurance outside their traditional working areas. GPs therefore, care for the members of a great number of sickness funds and private health insurers. This implies that under fundholding, GPs' budgets would have to consist of contributions from all those different third-party payers. That is not impossible. After all, despite the coexistence of different insurers, hospitals in the Netherlands are paid by a prospective global budget. However, this requires an information infrastructure that does not yet exist for pharmaceutical care. In the absence of a single-payer it is possible that the transaction costs of setting up and maintaining such an infrastructure are considerable.

In this respect it will be interesting to await the results of study that is currently being conducted in outpatient departments of hospitals [30]. In the Netherlands, inpatient drug prescriptions have always formed an integral part of the hospital budget. Drugs prescribed for ambulatory patients (which are now reimbursed per item by public and private health insurers) should in the near future also be integrated in the hospital budget. To that end, an experiment is taking place with a registration of ambulatory prescription in hospitals. 
Delnoij, D., Brenner, G.

Importing budget systems from other countries: what can we learn from the

German drug budget and the British GP fundholding?

Health Policy: 52, 2000, nr. 3, p. p. 157-169

In a budget system, the provision of feedback on expenditures to physicians is crucial. In most countries, large investments would have to be made in information systems that enable physicians to monitor prescribing costs. In the UK, the GPs had been provided with feedback on prescribing costs (the so-called Prescribing Analysis and Cost Data) since the early days of the NHS. The extra administrative costs for this element of the fundholding system were therefore minimal. In other countries, for instance in Italy, the feedback of prescription data on a national scale, is only being developed at the moment [31]. Policy makers should carefully balance the costs of such investments and the expected benefits of their reform. In France, for example, doctors are fined if they do not follow national rules for prescribing, ordering tests, and carrying out procedures. This system of mandatory practice guidelines was introduced in 1994 [32]. Durand et al. [33] reported that it took two months of full time work to check the prescriptions written by one doctor in 2 months. And this did not include the time spent retrieving the claims. In that case it is legitimate to wonder whether the gain is worth the effort.

The quality of the information infrastructure seems to be one of the most important factors for successfully implementing a budget system. Again, the example of the German drug budget is illustrative in this respect. In Germany, the drug budget was not so much 'imported' from another country, but from another sector in health care. Germany has a long tradition of imposing expenditure targets and caps on ambulatory physician services. Ambulatory physicians are paid on a fee-forservice basis. However, their reimbursement takes place in two stages. First the sickness funds pay the Kassenärztliche Vereinigungen (KV, associations of insurance doctors) an aggregate pool in exchange for all the services provided to sickness fund members. Then this aggregate pool is distributed by the KVs to their individual members. This distribution is based on a fee schedule and the individual service claims submitted by physicians. The conversion factor in that fee schedule has since 1978 been linked to the so-called Grundlohnsumme (the aggregate income of all sickness fund members) [34,35]. To put it simply, doctors submit claims of which the value is expressed in terms of points. Every 3 months the quarterly budget is divided by the total amount of points submitted by all the doctors in a $\mathrm{KV}$, resulting in a price per point. Individual doctors are then paid by multiplying the number of points they submitted by the price per point.

Because of this tradition of controlling expenditures by imposing caps, according to Saltman [22] the German global drug budget was consistent with the German social and political context. It reflected the application of what might be termed standard German procedure and according to Saltman the existing supervisory structure had the capacity to implement these new mechanisms effectively. Saltman argues that the success of the budget in reducing the pharmaceutical spending in the first year of operation can be seen as in substantial part reflecting their 'normalcy' in the German health care system. Yet, even in the German health care system, where so much experience is available in implementing and monitoring expenditure caps, the information infrastructure turned out to be the main bottleneck of the system.

To overcome the problems of monitoring a macro budget, it is intended to introduce 'individual' budgets in the form of speciality-related prescription limits. In the absence of fixed patient lists, however, it is unclear what the basis for such an individual, indicative budget should be, other than e.g. the average costs per physician practising the same speciality. However, differences in case mix (the number of patients treated and the type of morbidity) are probably the most important factor in explaining inter-doctor variation [36]. In the first version of the law by which the drug budget was introduced in 1993, there were some criteria for the creation of individual budgets. These included indications, chemical substances, volume of prescription, and the age-structure of the population. But these proved difficult to operationalise. In the revision of the law that took place in July 1997, these criteria have been omitted. Now the negotiating partners (sickness funds and physician associations) are free to contract on criteria.

Finally, a factor which is often overlooked when analysing prescribing costs is the role of the pharmacists. That is understandable, because historically pharmacists' role was restricted to delivering the prescriptions issued by doctors and were hence no important actor influencing prescribing costs. This role may change, though. In the Netherlands, for example, pharmacists can deliver any brandname or a generic in case the doctor has used the generic name of a medicine in his prescription. In that case, pharmacists too can play a role in generic substitution. 
Delnoij, D., Brenner, G.

Importing budget systems from other countries: what can we learn from the

German drug budget and the British GP fundholding?

Health Policy: 52, 2000, nr. 3, p. p. 157-169

\section{CONCLUSION}

Introducing a budget system can have a downward effect on prescribing costs, especially immediately after the introduction. In the long run, effects tend to diminish, both under macro expenditure caps as well as under individual microbudgets. This temporary effect may be enough for policy makers to aim introducing a budget system in their own country. However, they need to realise that not all types of budget systems can be implemented in every health care system. GP fundholding, for instance, is only possible in health care systems where GPs have fixed patient lists and act as a gatekeeper to higher specialised care, and it is much easier to introduce fundholding in single-payer, tax-based health care systems than in insurance-based systems with multiple third-party payers.

In general, a good information infrastructure is a necessary condition for implementing any budget system. Saltman and Figueras [2] argue that new reform strategies are often embraced by policy makers on ideological grounds, with little understanding of the technical resources required to put them in place. It is crucial that policy makers are not only aware of these technical requirements, but that they also balance the costs of investing in infrastructure against the expected gains from introducing a budget system.

\section{FIGURES}

$\%$ of Gross Domestic Product (GDP)

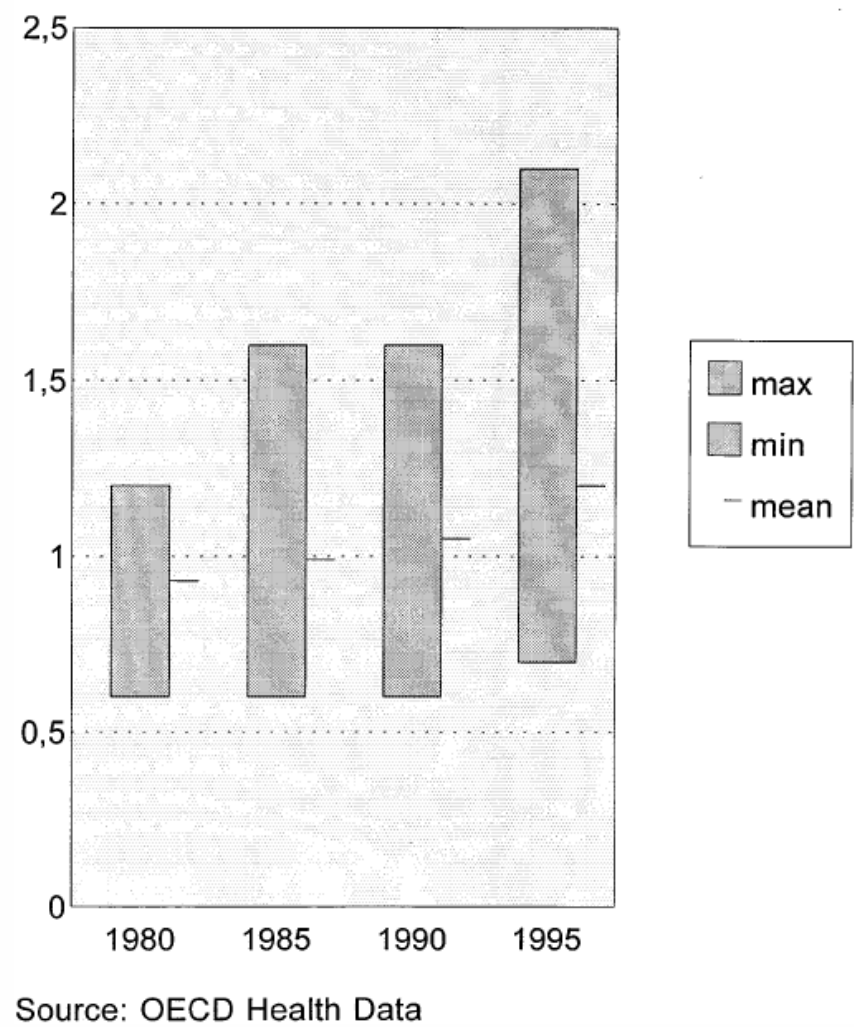

Fig. 1. Expenditures on pharmaceuticals in $15 \mathrm{EU}$ member states (\% of GDP, minimum, maximum) 
Delnoij, D., Brenner, G.

Importing budget systems from other countries: what can we learn from the

German drug budget and the British GP fundholding?

Health Policy: 52, 2000, nr. 3, p. p. 157-169

Mio. prescriptions

Sales in Mrd. DM

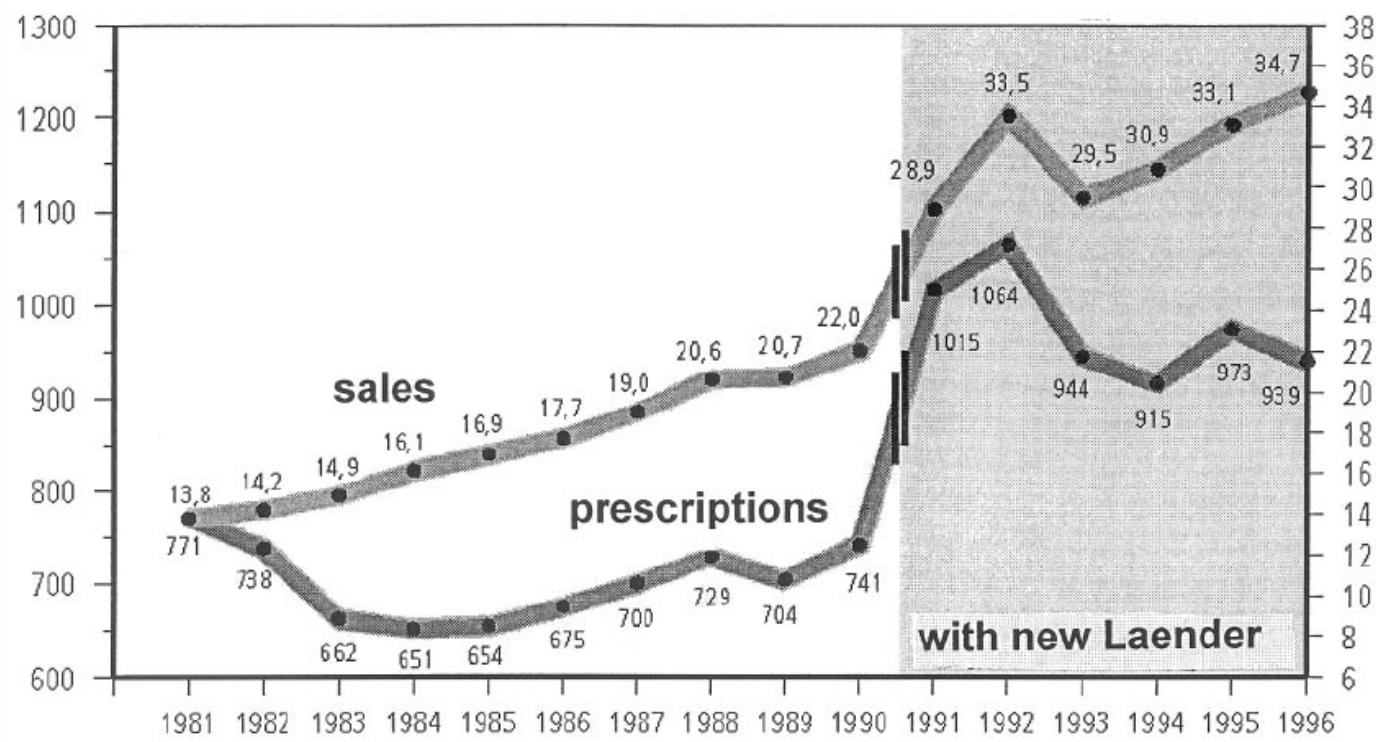

Quelle: Arzneiverordnungs-Report '97

Fig. 2. Prescriptions and sales of drugs of ambulatory care physicians on the social health insurance market in Germany between 1981 and 1996 (after 1991 with new Laender).

\section{REFERENCES}

[1] Hurst JW. Reforming health care in seven European nations. Health Affairs 1991;10(3):7-21.

[2] Saltman RB, Figueras J. European Health Care Reform. Analysis of current strategies.

Copenhagen: World Health Organization, Regional Office for Europe, 1997.

[3] Wilson RPH, Hatcher J, Barton S, Walley T. General practice fundholders' prescribing savings in one region of the United Kingdom, 1991-1994. Health Policy 1997;42:29-37.

[4] Audit Commission. What the Doctor Ordered. A study of GP Fundholders in England and Wales. London: HMSO, 1996

[5] Crump BJ, Cubbon MF, Drummond MF, Hawkes RA, Marchment MD. Fundholding in generalpractice and financial risk. British Medical Journal 1991;302:1582-4.

[6] Dixon J, Mays N. New Labour, new NHS. British Medical Journal 1997;315:1639-40.

[7] Le Grand J, Mays N, Mulligan JA, editors. Learning form the NHS Internal Market. A review of the

Evidence. London: King's Fund, 1998.

[8] Coulter A. Evaluating general practice fundholding in the United Kingdom. European Journal of Public Health 1995;5:233-9.

[9] Gosden T, Torgerson DJ. The effect of fundholding on prescribing and referral costs: a review of the evidence. Health Policy 1997;40:103-14.

[10] Bradlow J, Coulter A. Effect of fundholding and indicative prescribing schemes on general practitioners' prescribing costs. British Medical Journal 1993;307:1186-9.

[11] Maxwell M, Heaney D, Howie JGR, Noble S. General practice fundholding: observations on prescribing patterns and costs using the defined daily dose method. British Medical Journal 1993;307:1190-4.

[12] Wilson RPH, Buchan I, Walley T. Alterations in prescribing by general practitioner fundholders: an observational study. British Medical Journal 1995;311:1347-50.

[13] Wilson RPH, Hatcher J, Barton S, Walley T. Influences of practice characteristics on prescribing in fundholding and non-fundholding general practices: an observational study. British Medical Journal 1996;313:595-9.

[14] Stewart-Brown S, Surender R, Bradlow J, Coulter A, Doll H. The effects of fundholding in general practice on prescribing habits three years after introduction of the scheme. British Medical Journal 1995;311:1543-7.

[15] Brenner G. Drug policy and control of drug expenditure in Germany. Paper prepared for the Concerted Action Network for setting an evaluation team of control of drug expenditure in Europe, 
Delnoij, D., Brenner, G.

Importing budget systems from other countries: what can we learn from the

German drug budget and the British GP fundholding?

Health Policy: 52, 2000, nr. 3, p. p. 157-169

(contract number CHRX-CT-94 0700). Cologne, 1995 [16] Kamke K. The German health care system and health care reform. Health Policy 1998;43:171-94.

[17] Von der Schulenburg JMG. Management of cost and utilization of pharmaceuticals in Germany. Health Policy 1997;41(Suppl.):S45-53.

[18] Laschet H. Arznei- und Heilmittelbudget. Ein Datentableau, das viele Fragen aufwirft und die KBV massiv verärgert [Drug budget. Data that raise many questions and that annoy the KBV]. Ärzte Zeitung September 12, 1996, p. 6.

[19] Gü ther B. Auswirkungen des GSG auf das Verordnungsverhalten niedergelassener Ärzte [The effect of the health care reform law on the prescription behaviour of ambulatory physicians]. Gesundheitswesen 1995;57:185-91.

[20] Schö ffski O, von der Schulenburg JM. Unintended effects of a cost-containment policy: results of a natural experiment in Germany. Social Science and Medicine 1997;45:1537-9.

[21] Delnoij DMJ. Physician payment systems and cost control. Utrecht: NIVEL, 1994.

[22] Saltman RB. The context for health reform in the United Kingdom, Sweden, Germany, and the United States. Health Policy 1997;41(Suppl.):S9-S26.

[23] Kinberly JR, de Pouvourville G. Managerial innovation, migration, and DRGs. In: Kimberly JR, de Pouvourville G, editors. The migration of managerial innovation. San Francisco: Jossey-Bass Publishers, 1993, p. 1-16.

[24] Delnoij DMJ. Inschrijving patiënten op naam huisarts. Een Noors experiment [Personal lists in general practice. A Norwegian experiment]. Medisch Contact 1995;50:947-8.

[25] Vohlonen I, Pekurinen M, Saltman RB. Re-organizing primary medical care in Finland: the personal doctor program. Health Policy 1989;7:151-63.

[26] Marree' J, Groenewegen PP. Back to Bismarck: Eastern European Health Care Systems in transition. Aldershot: Avebury, 1997.

[27] Weiner JP, Ferriss DM. GP Budget Holding in the UK: Lessons from America. London: King's Fund Institute, 1990.

[28] Crebolder HFJM. Budgettering van en door huisartspraktijken [Fundholding in general practice]. Nederlands Tijd-schrift voor Genees-kunde 1992;136:1589-91.

[29] Delnoij DMJ, Stokx LJ. De huisarts: naast poortwachter nu ook rentmeester The GP: apart from the gatekeeper, now also the steward]. Medisch Contact 1993;48:747-9.

[30] Anonymous. Geneesmiddelen geteld [Counting drugs], NZi Notities 1999;68:8-9.

[31] Passamonti M, Pigni M, Sessa A, Ponti D. Italian general practitioners' knowledge of prescribing costs. European Journal of General Practice 1997;3:73-5.

[32] Dixon J. France seeks to curb health costs by fining doctors. Heavy handed and expensive. British Medical Journal 1997;315:895-6.

[33] Durand-Zalesky I, Colin C, Blum-Boisgard C. An attempt to save money by using mandatory practice guidelines in France. British Medical Journal 1997;315:943-6.

[34] Brenner G, Rublee DA. The 1987 revision of physician fees in Germany, Health Affairs 1991;(Fall):147-156.

[35] Blanke B, Kania H. Die Ökonomisierung der Gesundheitspolitik. Von der Globalsteuerung zum Wettbewerbskonzept im Gesundheitswesen [Economising health policy. From global steering to competition in health care]. Leviathan 1996;24:512-38.

[36] Delnoij DMJ, Spreeuwenberg PMM. Variation in GPs' referral rates to specialists in internal medicine. European Journal of Public Health 1997;7:427-35. 